\title{
Causes of death in remote symptomatic epilepsy
}

\author{
S.M. Day, PhD; Y.W. Wu, MD, MPH; D.J. Strauss, PhD, FASA; R.M. Shavelle, PhD, MBA; \\ and R.J. Reynolds, MPH
}

\begin{abstract}
Objective: To determine the causes of death of individuals with developmental disabilities that occur more frequently among those with remote symptomatic epilepsy (i.e., epilepsy occurring in persons with developmental delay or identified brain lesions) than for those without. Methods: The authors compared causes of mortality in persons with ( $\mathrm{n}=$ $10,030)$ and without $(\mathrm{n}=96,163)$ history of epilepsy in a California population of persons with mild developmental disabilities, 1988 to 2002. Subjects had traumatic brain injury, cerebral palsy, Down syndrome, autism, or a developmental disability with other or unknown etiology. There were 721,759 person-years of data, with 2,397 deaths. Underlying causes of death were determined from the State of California's official mortality records. Cause-specific death rates and standardized mortality ratios (SMRs) were computed for those with and without epilepsy relative to subjects in the California general population. Comparisons were then made between SMRs of those with and without epilepsy, and CIs on the ratios of SMRs were determined. Results: Death rates for persons with epilepsy were elevated for several causes. The greatest excess was due to seizures (International Classification of Diseases-9 [ICD-9] 345; SMR 53.1, 95\% CI 28.0 to 101.0) and convulsions (ICD-9 780.3; SMR 25.2, 95\% CI 11.7 to 54.2). Other causes occurring more frequently in those with epilepsy included brain cancer (SMR 5.2, 95\% CI 2.2 to 12.1), respiratory diseases (SMR 1.7, 95\% CI 1.2 to 2.5), circulatory diseases (SMR 1.3, 95\% CI 1.0 to 1.7), and accidents (SMR 2.7, 95\% CI 1.9 to 3.7), especially accidental drowning (SMR 12.8, 95\% CI 7.0 to 23.2). Conclusions: Remote symptomatic epilepsy is associated with an increased risk of death. Seizures, aspiration pneumonia, and accidental drowning are among the leading contributors.
\end{abstract}

NEUROLOGY 2005;65:216-222

Persons with epilepsy are at increased risk of death compared with the general population. ${ }^{1-7}$ Causes of death contributing to the increase include cancer, ${ }^{2,3,8}$ suicide, ${ }^{9-11}$ circulatory diseases,,$^{2,3}$ diseases of the digestive system,,$^{2,3}$ respiratory diseases, ${ }^{2,3}$ and accidental injury, ${ }^{3,6,8,11-14}$ especially drowning. ${ }^{6,8,12-14}$ Some deaths due to respiratory diseases, and other causes in persons with epilepsy are likely attributable to coexisting neurologic compromise ${ }^{6,15-17}$ As one study noted, "the main causes of death [among persons with epilepsy] are those most common in the population as a whole and those that underlie the epilepsy itself." 2

On the other hand, recent studies have identified sudden unexplained death in epilepsy (SUDEP) as a significant cause of death, ${ }^{18-20}$ accounting for up to $17 \%$ of deaths in persons with epilepsy. ${ }^{21}$ The definition of SUDEP varies between studies, however, and it is unclear how these findings can best impact clinical practice and prevention of mortality in epilepsy.

We compared mortality among persons with and without epilepsy in a large California population of persons with developmental disabilities. In the study population, $9 \%$ had at least a history of epilepsy. We sought to determine the causes of death that contribute to the excess death rate among persons with epilepsy.
Methods. Subjects. Our base population consisted of $>200,000$ persons with developmental disability who received services from the State of California Department of Developmental Services (DDS) between January 1988 and December 2002. The data and method of collection have been described elsewhere. ${ }^{1,5}$ In brief, persons in the base study population had "a disabling condition found to be closely related to mental retardation or to require treatment similar to that required for mentally retarded individuals." ${ }^{5}$ Subjects were evaluated approximately annually using the Client Development Evaluation Report (CDER). ${ }^{22}$ For further information on the data and their reliability, we refer the reader to previous studies. $1,5,16,17,23,24$

To reduce possible confounding effects of reduced mobility and severe cognitive deficits on mortality associated with epilepsy, we excluded persons with more severe disabilities. Thus, we excluded individuals unable to walk and climb stairs without support, those who were severely or profoundly mentally retarded, and persons with degenerative conditions. As we were interested in remote symptomatic epilepsy, persons thought to have idiopathic epilepsy were also excluded.

We selected subjects ages 5 to 69 (mean age at first evaluation 19.3 , SD 12.8 ; $57 \%$ male) during the 15 -year study period from 1988 to 2002. Specifically, the beginning of the period "at risk" for a given subject was the date of the first CDER evaluation or January 1, 1988, whichever came later. The end of the subject's period at risk was the earliest of 1) the date of death, 2) the end of the study period (December 31, 2002), and 3) 3 years after the date of the subject's last CDER. This last condition was included to minimize the potential bias due to subjects who may have left California. Deaths of such persons would not be in our records, but because of condition 3 , these subjects would also not be counted as being at risk for more than a fairly short period.

Sources of clinical information. Epilepsy was identified from three items on the CDER: type of seizure, seizure frequency, and

From the Life Expectancy Project (Drs. Day, Strauss, Shavelle, R.J. Reynolds), San Francisco, CA; and the Department of Pediatrics and Neurology (Dr. Wu), University of California at San Francisco.

Received January 20, 2004. Accepted in final form April 8, 2005.

Address correspondence and reprint requests to Dr. S.M. Day, Life Expectancy Project, 1439 17th Ave., San Francisco, CA 94122-3402; e-mail: Day@LifeExpectancy.com 
"status epilepticus in the last year (yes/no)." Seizure type was coded as eight types, from "partial with elementary symptomatology" to "generalized tonic-clonic (grand mal)" (GTC). Seizure frequency was coded according to eight levels, ranging from "history of seizures, none in 2 years" to "more than one per day." Personyears for which a type of seizure was indicated as unknown, or for which a type was indicated but no frequency information was specified, were excluded. These exclusions resulted in a reduction of $8 \%$ of total person-years. Remaining subjects with at least a history of epilepsy contributed 65,126 person-years of data, with 406 deaths.

Mortality information, including ICD-9 codes for underlying cause of death, was obtained from annual computer files from the California Department of Health Services ${ }^{25}$ and matched against the subjects on the basis of name, date of birth, and social security number when available. For the years 1999 to 2002, ICD-9 codes were converted from ICD-10.

The epilepsy person-years were further stratified according to severity level, as defined in a previous study. ${ }^{5}$ Severity levels considered here are as follows: NE, no history of epilepsy; E1, history of epilepsy but no seizures in $\geq 1$ year; E2, seizures within the last year, or more recently/frequently, but no recent GTC seizures; E3, GTC seizures within the last year, or more recently/ frequently.

For some comparisons, all levels of epilepsy are combined and denoted as E123. Those with a history of seizures within the last year are combined and denoted as E23.

Standardized mortality ratios (SMRs) comparing the study populations (those with or without a history of epilepsy) with the California general population were computed as follows: 1) For each cause of death considered, age-specific mortality rates (deaths per 100,000 person-years of exposure) in the California general population were computed using State of California mortality and population data over the period 1988 to $2002^{26-28}$; 2) for each age group, person-years at risk of death for those in the study with and without epilepsy were determined; 3) mortality rates from Step 1 were applied to the exposure times in Step 2 to determine expected numbers of death due to each cause within each age group; 4) for each study group, the observed numbers of deaths due to each cause and in each age group were recorded; 5) the ratios of the numbers obtained in Steps 3 and 4 are SMRs. ${ }^{29}$ By summing observed and expected numbers of deaths over age groups, overall SMRs for each cause were computed for those with (E123) and without (NE) epilepsy.

To compare the mortality rates for persons in the study population with epilepsy with those without, the ratio of SMRs was calculated as SMR-E123/SMR-NE. CIs for the ratio of SMRs were determined as follows: 1) The number of observed deaths in the two study populations were assumed to be Poisson random variables, whereas the observed numbers of deaths in the California general population were treated as known (not random); 2) CIs were calculated as the estimated ratio (SMR-E123/SMR-NE) \pm 1.96 times the estimated variance of the ratio; 3) the variance of the ratio was approximated using the "delta" method, a standard statistical method for estimating the variance of a function of two random variables. ${ }^{30}$ In this case, the function is the ratio of two SMRs, each of which is assumed to be the ratio of a Poisson random variable and a fixed number. The Poisson random variable is the number of observed deaths (in the epilepsy group and in the no-epilepsy group). The fixed number is the number of expected deaths in the California general population. Although this number is not actually fixed, for large sample sizes, this assumption is an acceptable approximation.

Kahn and Sempos ${ }^{29}$ discuss the method of comparing two populations by computing the ratio of their SMRs. This ratio is to be thought of as an estimate of the SMR that might be obtained by applying mortality rates in the no-epilepsy group directly to exposure in the epilepsy group. Because numbers of deaths due to many causes in the no-epilepsy group are insufficient to provide stable mortality rates, we have opted for this indirect comparison. Though this ratio could be a slightly biased estimate of the direct SMR, as Kahn and Sempos ${ }^{29}$ point out, it is difficult to find practical examples in which such a comparison is the source of substantial error. A comparison of the direct and indirect calculations of SMRs for those causes of death with sufficient numbers to give stable mortality rates in the no-epilepsy group showed very little difference (results not shown).
Using the same source of mortality information to determine causes of death for both the study groups and the general California population minimized the effect of potential reporting bias on the SMRs.

Results. Thus, 106,193 persons were included in the study. They had traumatic brain injury (1.6\%), cerebral palsy $(3.9 \%)$, autism $(13.8 \%)$, and chromosomal anomalies (11.5\%; mostly Down syndrome). The majority of the subjects $(69 \%)$ had none of these conditions and were coded as "other." Within this latter group, the majority had mild or moderate mental retardation of unknown or unidentified etiology.

Table 1 gives demographic information separately for persons with and without a history of epilepsy as well as a breakdown of the person-years of exposure, with the exposure for those with a history of epilepsy broken down further by the severity scale described previously. ${ }^{5}$

Within the 656,632 person-years of exposure for the no-epilepsy group, there were 1,991 observed deaths, giving a crude mortality rate of 3.03 deaths/1,000 person-years. For those with epilepsy, there were 65,126 person-years and 406 deaths, giving a crude rate of 6.23 deaths $/ 1,000$ person-years. Based on age-specific rates in the no-epilepsy group, the expected number of deaths for the epilepsy group was 161, giving 245 excess deaths overall. More than two-thirds $(166 ; 68 \%)$ of the excess deaths were attributable to combined causes of epilepsy and convulsions, other CNS disorders, accidental drowning, brain cancer, aspiration pneumonia, and unknown causes (ICD-9 799.9).

Table 2 gives the cause-specific numbers of observed deaths in the epilepsy and no-epilepsy groups, resulting SMRs for those with and without epilepsy, and ratios of these (SMR-E123/SMR-NE), with CIs on the ratios. The ratios SMR-E123/SMR-NE indirectly compare observed deaths in the study group with epilepsy with numbers expected based on mortality rates of those without epilepsy. Unless otherwise specified, "SMR" will henceforth refer to this ratio of SMRs comparing those with epilepsy with those without (SMR-E123/SMR-NE). Comparisons with the California general population will be referred to as "GP SMRs."

The GP SMRs $(95 \%$ CIs) for all causes combined were 4.0 (3.6 to 4.3 ) for those with epilepsy and 1.9 (1.8 to 2.0 ) for those without; thus, the overall SMR comparing those with epilepsy with those without was 2.1 (1.9 to 2.3). Numbers of deaths due to several causes were elevated among persons with a history of epilepsy. The most pronounced increases were for causes obviously related to the epilepsy itself, including status epilepticus (ICD-9 345.2; SMR 156.6, 95\% CI 20.8 to 1180.7), epilepsy other than status epilepticus (ICD-9 345, excluding 345.2; SMR 53.1, 95\% CI 28.0 to 101.0), and convulsions (ICD-9 780.3; SMR 25.2, $95 \%$ CI 11.7 to 54.2 ).

Accidental deaths showed an overall increase for persons with epilepsy (ICD-9 E800-E849, E880-E930; SMR $2.7,95 \%$ CI 1.9 to 2.7 ), with drowning being the single most significant accidental cause of death (ICD-9 E910; SMR 12.8, 95\% CI 7.0 to 23.2).

Cancer deaths in general were only slightly increased (ICD-9 140-208; SMR 1.3, 95\% CI 0.9 to 1.8). There was not a difference in tobacco-related cancer deaths between the epilepsy and no-epilepsy groups (SMR 1.0, NS). Further, deaths due to tobacco-related cancers ${ }^{31}$ were not in- 


\begin{tabular}{|c|c|c|c|c|c|c|c|c|}
\hline \multirow[b]{3}{*}{ Characteristic $\ddagger$} & \multicolumn{4}{|c|}{ Persons* } & \multicolumn{4}{|c|}{ Person-years $\dagger$} \\
\hline & \multicolumn{2}{|c|}{$\begin{array}{l}\text { History of } \\
\text { epilepsy, } \\
\mathrm{n}=10,030\end{array}$} & \multicolumn{2}{|c|}{$\begin{array}{l}\text { No history of } \\
\text { epilepsy, } \\
\mathrm{n}=96,163\end{array}$} & \multicolumn{2}{|c|}{$\begin{array}{l}\text { History of } \\
\text { epilepsy, } \\
\mathrm{n}=65,126\end{array}$} & \multicolumn{2}{|c|}{$\begin{array}{l}\text { No history of } \\
\text { epilepsy, } \\
\mathrm{n}=656,632\end{array}$} \\
\hline & $\mathrm{n}$ & $\%$ & $\mathrm{n}$ & $\%$ & $\mathrm{n}$ & $\%$ & $\mathrm{n}$ & $\%$ \\
\hline Deaths & 406 & 4.0 & 1,991 & 2.1 & 406 & 0.6 & 1,991 & 0.3 \\
\hline \multicolumn{9}{|l|}{ Sex } \\
\hline Male & 5,751 & 57.3 & 59,126 & 61.5 & 37,107 & 57.0 & 392,954 & 59.8 \\
\hline Female & 4,279 & 42.7 & 37,037 & 38.5 & 28,020 & 43.0 & 263,678 & 40.2 \\
\hline \multicolumn{9}{|l|}{ Etiology of disability } \\
\hline Traumatic brain injury & 496 & 4.9 & 1,239 & 1.3 & 3,021 & 4.6 & 7,931 & 1.2 \\
\hline Cerebral palsy & 846 & 8.4 & 3,268 & 3.4 & 5,722 & 8.8 & 25,183 & 3.8 \\
\hline Chromosomal anomaly & 778 & 7.8 & 11,386 & 11.8 & 4,677 & 7.2 & 73,182 & 11.2 \\
\hline Autism & 447 & 4.5 & 14,195 & 14.8 & 2,409 & 3.7 & 66,863 & 10.2 \\
\hline Other and unknown & 7,463 & 74.4 & 66,075 & 68.7 & 49,297 & 75.7 & 483,473 & 73.6 \\
\hline \multicolumn{9}{|l|}{ Epilepsy scale } \\
\hline No history of epilepsy & 215 & 2.1 & 96,163 & 100.0 & - & - & 656,632 & 100.0 \\
\hline History, none in $\geq 1 \mathrm{y}$ & 2,941 & 29.3 & - & - & 20,314 & 31.2 & - & - \\
\hline Recent seizures, not tonic-clonic & 3,311 & 33.0 & - & - & 20,692 & 31.8 & - & - \\
\hline Recent tonic-clonic seizures & 3,563 & 35.5 & - & - & 24,702 & 37.9 & - & - \\
\hline \multicolumn{9}{|l|}{ Age, $\mathrm{y}($ mean $=19.3, \mathrm{SD}=12.8)$} \\
\hline $5-9$ & 2,154 & 21.5 & 29,803 & 31.0 & 5,310 & 8.2 & 80,892 & 12.3 \\
\hline $10-19$ & 3,120 & 31.1 & 29,056 & 30.2 & 16,349 & 25.1 & 161,670 & 24.6 \\
\hline $20-29$ & 2,390 & 23.8 & 18,839 & 19.6 & 18,534 & 28.5 & 168,852 & 25.7 \\
\hline $30-39$ & 1,426 & 14.2 & 10,595 & 11.0 & 14,050 & 21.6 & 132,116 & 2.0 \\
\hline $40-70$ & 940 & 9.4 & 7,870 & 8.2 & 10,884 & 16.7 & 113,102 & 17.2 \\
\hline \multicolumn{9}{|l|}{ Word usage } \\
\hline No use of words & 281 & 2.8 & 3,201 & 3.3 & 1,633 & 2.5 & 20,011 & 3.1 \\
\hline $\begin{array}{l}\text { Uses simple (one-syllable) words and } \\
\text { associates words with appropriate } \\
\text { objects }\end{array}$ & 1,427 & 14.2 & 21,312 & 22.2 & 9,146 & 14.0 & 134,914 & 20.5 \\
\hline $\begin{array}{l}\text { Uses complex words and associates } \\
\text { words with appropriate objects but } \\
\text { has a limited vocabulary }\end{array}$ & 4,133 & 41.2 & 43,717 & 45.5 & 27,331 & 42.0 & 302,690 & 46.1 \\
\hline $\begin{array}{l}\text { Has a broad vocabulary, understands } \\
\text { meaning of words, and uses them } \\
\text { in appropriate contexts }\end{array}$ & 4,189 & 41.8 & 27,933 & 29.0 & 27,016 & 41.5 & 199,017 & 30.3 \\
\hline \multicolumn{9}{|l|}{ Receptive language } \\
\hline Does not understand speech & 63 & 0.6 & 677 & 0.7 & 429 & 0.7 & 5,344 & 0.8 \\
\hline Understands simple words & 248 & 2.5 & 3,189 & 3.3 & 1,391 & 2.1 & 17,038 & 2.6 \\
\hline $\begin{array}{l}\text { Understand simple phrases or } \\
\text { instructions }\end{array}$ & 1,602 & 16.0 & 22,331 & 23.2 & 9,982 & 15.3 & 132,345 & 20.2 \\
\hline $\begin{array}{l}\text { Understands simple conversation and } \\
\text { combination of instructions }\end{array}$ & 5,110 & 50.9 & 51,238 & 53.3 & 33,710 & 51.8 & 362,601 & 55.2 \\
\hline $\begin{array}{l}\text { Understand meaning of story plot and } \\
\text { complex conversation }\end{array}$ & 3,007 & 30.0 & 18,728 & 19.5 & 19,614 & 30.1 & 139,304 & 21.2 \\
\hline
\end{tabular}

\footnotetext{
* A person is counted as having a history of epilepsy if the individual was so designated on any Client Development Evaluation Report evaluation during the study period.

$\dagger$ A person-year is counted as having a history of epilepsy if the individual contributing the person-year is so designated on the Client Development Evaluation Report for that year.

$\ddagger$ Characteristics other than epilepsy are measured on the first observation for an individual during the study period.
} 
Table 2 Comparison of SMRs for persons with (E123) and without (NE) a history of epilepsy

\begin{tabular}{|c|c|c|c|c|c|c|}
\hline Category (ICD-9) & $\begin{array}{c}\text { Obs } \\
(\mathrm{E} 123)^{*}\end{array}$ & $\begin{array}{l}\mathrm{Obs} \\
(\mathrm{NE})^{*}\end{array}$ & $\begin{array}{c}\text { SMR } \\
(\mathrm{E} 123) \dagger\end{array}$ & $\begin{array}{c}\mathrm{SMR} \\
(\mathrm{NE}) \dagger\end{array}$ & $\begin{array}{c}\text { Ratio SMR } \\
(\mathrm{E} 123) / \mathrm{SMR}(\mathrm{NE})\end{array}$ & $95 \% \mathrm{CI}$ \\
\hline All malignant neoplasms (140-208) & 36 & 298 & 1.8 & 1.4 & 1.3 & $0.9-1.8$ \\
\hline Tobacco-related cancers & 8 & 90 & 0.9 & 0.9 & 1.0 & $0.5-2.0$ \\
\hline Leukemia (other than myeloid) & 2 & 33 & 2.7 & 4.4 & 0.6 & $0.2-2.6$ \\
\hline Cancer of brain (191) & 8 & 16 & 7.4 & 1.4 & 5.2 & $2.2-12.1$ \\
\hline $\begin{array}{l}\text { Other cancers (140-208 not mentioned } \\
\text { elsewhere) }\end{array}$ & 18 & 159 & 1.9 & 1.5 & 1.2 & $0.7-2.0$ \\
\hline Digestive system (520-579) & 6 & 85 & 1.2 & 1.7 & 0.7 & $0.3-1.7$ \\
\hline All accidents (E800-E849, E880-E930) & 46 & 165 & 2.5 & 0.9 & 2.7 & $1.9-3.7$ \\
\hline Accidental drowning (E910) & 25 & 19 & 28.7 & 2.2 & 12.8 & $7.0-23.2$ \\
\hline Road traffic accidents $(810-819,826-828)$ & 7 & 75 & 0.7 & 0.7 & 0.9 & $0.4-1.9$ \\
\hline Accidental falls (880-888) & 1 & 13 & 1.5 & 2.0 & 0.8 & $0.1-5.8$ \\
\hline Poisonings (850-869) & 2 & 14 & 3.1 & 2.2 & 1.4 & $0.3-6.2$ \\
\hline $\begin{array}{l}\text { Other accidents (800-949 not mentioned } \\
\text { elsewhere) }\end{array}$ & 11 & 44 & 4.6 & 1.9 & 2.4 & $1.3-4.7$ \\
\hline All circulatory diseases (390-459) & 61 & 509 & 3.4 & 2.6 & 1.3 & $1.0-1.7$ \\
\hline Ischemic heart disease (410-414) & 27 & 181 & 3.4 & 2.1 & 1.7 & $1.1-2.5$ \\
\hline Pulmonary circulation (415-417) & 5 & 24 & 11.3 & 5.3 & 2.1 & $0.8-5.6$ \\
\hline Cerebrovascular disease (430-438) & 7 & 73 & 2.6 & 2.5 & 1.0 & $0.5-2.2$ \\
\hline Other vascular disease (440-448) & 1 & 27 & 1.5 & 3.7 & 0.4 & $0.1-3.0$ \\
\hline $\begin{array}{l}\text { Other circulatory disease (390-459 not } \\
\text { mentioned elsewhere) }\end{array}$ & 21 & 204 & 3.4 & 3.1 & 1.1 & $0.7-1.7$ \\
\hline $\begin{array}{l}\text { Respiratory, incl. aspiration pneumonia } \\
\text { and accidental inhalation }(460-519)\end{array}$ & 33 & 209 & 8.4 & 4.9 & 1.7 & $1.2-2.5$ \\
\hline Pneumonia not aspiration (480-487.0) & 10 & 91 & 7.9 & 6.8 & 1.2 & $0.6-2.2$ \\
\hline $\begin{array}{l}\text { Aspiration pneumonia, including } \\
\text { accidental inhalation (507, E911- } \\
\text { E912) }\end{array}$ & 10 & 35 & 53.0 & 17.8 & 3.0 & $1.5-6.0$ \\
\hline $\begin{array}{l}\text { Other respiratory (460-519 not } \\
\text { mentioned elsewhere) }\end{array}$ & 13 & 83 & 5.2 & 3.0 & 1.7 & $1.0-3.1$ \\
\hline Nervous system (320-389) & 95 & 61 & 55.6 & 3.5 & 15.9 & $11.6-22.0$ \\
\hline Alzheimer (331-331.1) & 1 & 10 & 22.7 & 18.9 & 1.2 & $0.2-9.4$ \\
\hline Epilepsy (354) & 61 & 11 & 315.4 & 5.9 & 53.1 & $28.0-101.0$ \\
\hline Status epilepticus (345.2) & 16 & 1 & 285.1 & 1.8 & 156.6 & $20.8-1,180.7$ \\
\hline $\begin{array}{l}\text { Other nervous system (320-389 not } \\
\text { mentioned elsewhere) }\end{array}$ & 17 & 39 & 12.0 & 2.7 & 4.5 & $2.5-7.9$ \\
\hline Endocrine (240-279) & 4 & 47 & 4.6 & 5.4 & 0.9 & $0.3-2.4$ \\
\hline Diabetes (250) & 5 & 46 & 2.8 & 2.5 & 1.2 & $0.5-2.9$ \\
\hline Dementia (294.1) & 0 & 1 & 0.0 & 12.9 & 0.0 & $0.0-0.0$ \\
\hline Congenital anomalies (740-759) & 21 & 214 & 23.6 & 23.9 & 1.0 & $0.6-1.5$ \\
\hline Convulsions (780.3) & 24 & 9 & 192.1 & 7.6 & 25.2 & $11.7-54.2$ \\
\hline Suicides (E950-E959) & 2 & 13 & 0.3 & 0.2 & 1.5 & $0.3-6.5$ \\
\hline Unknown cause (799) & 22 & 42 & 17.3 & 3.4 & 5.0 & $3.0-8.5$ \\
\hline All other & 51 & 292 & 2.2 & 1.3 & 1.7 & $1.2-2.3$ \\
\hline
\end{tabular}

* Number of observed deaths in the epilepsy (E123) or no-epilepsy (NE) group.

$\dagger$ SMR for the epilepsy or no-epilepsy group, computed as the observed number of deaths in the specified group divided by the expected number based on mortality rates in the California general population (expected number not shown).

SMR = standardized mortality ratio; E123 = history of epilepsy (any type or frequency); NE = no history of epilepsy; ICD-9 = International Classification of Diseases-9. 
Table 3 SMRs for selected causes of death: People with a history of epilepsy but no seizure in $\geq 1$ year compared with those without a history of epilepsy

\begin{tabular}{|c|c|c|c|c|c|c|}
\hline Category (ICD-9) & $\begin{array}{l}\text { Obs } \\
(\mathrm{E} 1)^{*}\end{array}$ & $\begin{array}{l}\mathrm{Obs} \\
(\mathrm{NE})^{*}\end{array}$ & $\begin{array}{l}\text { SMR } \\
(\mathrm{E} 1) \dagger\end{array}$ & $\begin{array}{l}\mathrm{SMR} \\
(\mathrm{NE}) \dagger\end{array}$ & $\begin{array}{c}\text { Ratio SMR } \\
\text { (E1)/ SMR (NE) }\end{array}$ & $95 \% \mathrm{CI}$ \\
\hline Accidental drowning (E910) & 4 & 19 & 15.1 & 2.3 & 6.7 & $2.3-19.6$ \\
\hline $\begin{array}{l}\text { Aspiration pneumonia, including accidental } \\
\text { inhalation (507, E911-E912) }\end{array}$ & 2 & 35 & 31.2 & 18.0 & 1.7 & $0.4-7.2$ \\
\hline Epilepsy (354) & 4 & 11 & 63.7 & 6.0 & 10.6 & $3.4-33.4$ \\
\hline Convulsions (780.3) & 5 & 9 & 123.7 & 7.7 & 16.1 & $5.4-47.9$ \\
\hline Unknown cause (799) & 2 & 41 & 4.7 & 3.4 & 1.4 & $0.3-5.8$ \\
\hline
\end{tabular}

* Number of observed deaths in the epilepsy or no-epilepsy group.

$\dagger$ SMR for the epilepsy or no-epilepsy group, computed as the observed number of deaths in the specified group divided by the expected number based on mortality rates in the California general population (expected number not shown).

$\mathrm{SMR}=$ standardized mortality ratio; E1 = history of epilepsy (any seizure type), but no events in the last $12 \mathrm{mo}$; NE = no history of epilepsy; ICD-9 = International Classification of Diseases-9.

creased in either study group compared with the California general population (GP SMRs 0.9 in both cases, NS). Cancers of lung and bronchus were underrepresented in both cases (ICD-9 162; GP SMRs 0.2 for the epilepsy group and 0.4 for the no-epilepsy group). Deaths due to brain cancer were not significantly increased for the no-epilepsy group compared with the California general population (ICD-9 191; GP SMR 1.4, NS), but the epilepsy group did show a significant increase in these tumor deaths compared with both the California general population (GP SMR 7.4; 95\% CI 3.2 to 14.5) and the study group without epilepsy (SMR $5.2 ; 95 \%$ CI 2.2 to 12.1 ).

"Other unknown and unspecified causes of death" (ICD-9 799.9) were elevated in both the no-epilepsy (GPSMR 3.3; 95\% CI 2.3 to 4.4) and epilepsy (GP-SMR 17.3; 95\% CI 10.8 to 26.2 ) groups compared with the California general population and for those with epilepsy compared to those without (SMR 5.0; 95\% CI 3.0 to 8.5).

Tables 3 and 4 illustrate for selected causes of death the effect on SMRs of severity of epilepsy, using the scale described above. ${ }^{1,5}$ Though numbers of deaths were too few for many causes to consider them separately by severity level, there is a clear pattern of increasing SMRs by increasing severity for those causes with sufficient numbers to consider.

Discussion. Although it is not surprising that persons with epilepsy are at increased risk of death due to seizures or convulsions, this result has not been widely reported. Persons with epilepsy dying of unobserved seizures could account at least in part for the increased number of deaths due to unknown causes (799.9) seen in our cohort. Given the large increases in deaths due to seizures and convulsions among those with epilepsy, one might expect a number of deaths due to unobserved seizures. Many studies have identified SUDEP as a common cause of

Table 4 SMRs for selected causes of death: People with recent seizures compared with those without a history of epilepsy

\begin{tabular}{|c|c|c|c|c|c|c|}
\hline Category (ICD-9) & $\begin{array}{l}\text { Obs } \\
(\mathrm{E} 23)^{*}\end{array}$ & $\begin{array}{l}\text { Obs } \\
(\mathrm{NE})^{*}\end{array}$ & $\begin{array}{c}\text { SMR } \\
(\mathrm{E} 23) \dagger\end{array}$ & $\begin{array}{l}\mathrm{SMR} \\
(\mathrm{NE}) \dagger\end{array}$ & $\begin{array}{c}\text { Ratio SMR } \\
\text { (E23)/SMR (NE) }\end{array}$ & $95 \% \mathrm{CI}$ \\
\hline Accidental drowning (E910) & 21 & 19 & 35.9 & 2.3 & 15.8 & $7.2-34.7$ \\
\hline $\begin{array}{l}\text { Aspiration pneumonia, including accidental } \\
\text { inhalation (507, E911-E912) }\end{array}$ & 8 & 35 & 66.4 & 18.0 & 3.7 & $0.2-71.1$ \\
\hline Epilepsy (354) & 57 & 11 & 451.2 & 6.0 & 75.3 & $31.6-179.3$ \\
\hline Convulsions (780.3) & 19 & 9 & 232.5 & 7.7 & 30.2 & $7.4-123.5$ \\
\hline Unknown cause (799) & 20 & 41 & 24.3 & 3.4 & 7.2 & $3.0-17.0$ \\
\hline
\end{tabular}

* Number of observed deaths in the epilepsy or no-epilepsy group.

$\uparrow$ SMR for the epilepsy or no-epilepsy group, computed as the observed number of deaths in the specified group divided by the expected number based on mortality rates in the California general population (expected number not shown).

$\mathrm{SMR}=$ standardized mortality ratio; E23 = seizures in the last 12 mo (any seizure type); NE = no history of epilepsy; ICD-9 = International Classification of Diseases-9. 
death in persons with epilepsy. The literature varies in defining SUDEP, ${ }^{18-21}$ though most definitions require that the death be sudden and nonaccidental, occurring within 1 day of the onset of symptoms, or sometimes within 1 or 2 hours; a history of diagnosed epilepsy; and no anatomic or toxicologic cause of death identified. Some have argued that this last requirement often means an autopsy must be performed to confirm SUDEP, and this precludes such a determination in the present study, in which we have relied on underlying causes of death as indicated in California State mortality files. Nevertheless, many of the significant numbers of deaths due to seizures and unknown causes (ICD-9 799.9) among those in the present study with a history of epilepsy are potentially attributable to SUDEP.

The increased number of deaths due to brain tumors is most likely related to increased likelihood of such tumors among persons experiencing seizures. The increase in deaths due to accidental drowning has been reported by others. ${ }^{6,8,12-14}$ This is an important finding, as these deaths are arguably preventable. ${ }^{12}$

Our study has some important limitations. Because persons in both study populations had a variety of developmental disabilities, findings may not generalize directly to all individuals with epilepsy. Mortality rates in both study populations were higher than those of the California general population for several causes of death, including seizures, respiratory diseases, and epilepsy. Both study populations had fewer than expected numbers of deaths due to cancer of the lung and bronchus (not shown in table 2). These differences have been documented in other studies of causes of death for various groups receiving services from the California DDS, including those with autism, ${ }^{32}$ traumatic brain injury, ${ }^{16}$ cerebral palsy, ${ }^{17}$ and Down syndrome. ${ }^{33}$ In spite of the special nature of the study populations, however, the excess numbers of deaths due to some causes (e.g., seizures, aspiration, and accidental drowning) must at least in part be attributable to epilepsy.

A second limitation is that subjects with no previous history of epilepsy who die suddenly from the effects of a seizure would not be identified here as having epilepsy, and it may well be that the study subjects without a history of epilepsy were nonetheless at greater risk of having seizures than the California general population. Many in this group had known brain injuries (birth injuries or acquired traumatic brain injuries), and this is known to be associated with increased risk of seizures. ${ }^{24,34,35}$ This may partly explain the increased number of "unknown" causes of death, and causes related to epilepsy, in the no-epilepsy group (see table 2).

The study has some important strengths by comparison to previous reports of cause-specific epilepsy mortality. The size of the study makes this one of the largest population-based studies of cause-specific mortality in epilepsy. The significant numbers of observed deaths allowed us to make detailed comparisons for many different causes of deaths. Also, the indirect method of comparing mortality in the epilepsy and no-epilepsy groups, by considering the ratio of their GP SMRs, is robust to small differences in underlying age distributions and offers relatively stable measures of excess risks due to epilepsy. Finally, as mentioned earlier, we have used the same source of mortality information for both study populations and for the California general population, thus reducing many potential sources of bias in comparing mortality rates.

The causes of death identified here that occur more frequently in persons with epilepsy are perhaps predictable. It has long been known, for example, that accidental drowning is a serious risk for persons with epilepsy. As the parent of one victim put it, however, "There was no chance for anyone to save him. I think we were blissfully ignorant.... The whole business of epilepsy should be explained properly. You almost need someone to go through it with you." 12 The present study adds to the body of knowledge of mortality risk for persons with epilepsy and may serve as a reminder of that risk for physicians and other caregivers.

\section{References}

1. Day S, Strauss D, Shavelle R, Wu YW. Excess mortality in remote symptomatic epilepsy. J Insur Med 2003;35:155-160.

2. Morgan CL, Kerr MP. Epilepsy and mortality: a record linkage study in a U.K. population. Epilepsia 2002;43:1251-1255

3. Nilsson L, Tomson T, Farahmand BY, Diwan V, Persson PG. Causespecific mortality in epilepsy: a cohort study of more than 9,000 patients once hospitalized for epilepsy. Epilepsia 1997;38:1062-1068.

4. Shackleton DP, Westendorp RG, Kasteleijn-Nolst Trenite DG, de Craen AJ, Vandenbroucke JP. Survival of patients with epilepsy: an estimate of the mortality risk. Epilepsia 2002;43:445-450.

5. Strauss DJ, Day SM, Shavelle RM, Wu YW. Remote symptomatic epilepsy: does seizure severity increase mortality? Neurology 2003;60:395399.

6. Breningstall GN. Mortality in pediatric epilepsy. Pediatr Neurol 2001; 25:9-16.

7. Nashef L, Shorvon SD. Mortality in epilepsy. Epilepsia 1997;38:10591061.

8. Sheth SG, Krauss G, Krumholz A, Li G. Mortality in epilepsy: driving fatalities vs other causes of death in patients with epilepsy. Neurology 2004;63:1002-1007.

9. Barraclough BM. The suicide rate of epilepsy. Acta Psychiatr Scand 1987;76:339-345.

10. Jones JE, Hermann BP, Barry JJ, Gilliam FG, Kanner AM, Meador KJ. Rates and risk factors for suicide, suicidal ideation, and suicide at tempts in chronic epilepsy. Epilepsy Behav 2003;4(suppl 3):S31-S38.

11. Rafnsson V, Olafsson E, Hauser WA, Gudmundsson G. Cause-specific mortality in adults with unprovoked seizures. A population-based incidence cohort study. Neuroepidemiology 2001;20:232-236.

12. Besag FM. Lesson of the week: tonic seizures are a particular risk factor for drowning in people with epilepsy. Br Med J 2001;322:975-976.

13. Diekema DS, Quan L, Holt VL. Epilepsy as a risk factor for submersion injury in children. Pediatrics 1993;91:612-616.

14. Kemp AM, Sibert JR. Epilepsy in children and the risk of drowning. Arch Dis Child 1993;68:684-685.

15. Goldacre MJ, Roberts SE, Griffith M. Place, time and certified cause of death in people who die after hospital admission for myocardial infarction or stroke. Eur J Public Health 2004;14:338-342.

16. Shavelle RM, Strauss D, Whyte J, Day SM, Yu YL. Long-term causes of death after traumatic brain injury. Am J Phys Med Rehabil 2001;80: 510-519.

17. Strauss D, Cable W, Shavelle R. Causes of excess mortality in cerebral palsy. Dev Med Child Neurol 1999;41:580-585.

18. Antoniuk SA, Oliva LV, Bruck I, Malucelli M, Yabumoto S, Castellano JL. Sudden unexpected, unexplained death in epilepsy autopsied patients. Ar Qneuropsiquiatr 2001;59:40-45.

19. Langan Y. Sudden unexpected death in epilepsy (SUDEP): risk factors and case control studies. Seizure 2000;9:179-183.

20. Nashef L, Brown S. Epilepsy and sudden death. Lancet 1996;348:13241325.

21. Lhatoo SD, Sander JW. Sudden unexpected death in epilepsy. Hong Kong Med J 2002;8:354-358. 
22. Client Development Evaluation Report. In. Sacramento: California Department of Developmental Services, 1986.

23. Strauss DJ, Shavelle RM, Anderson TW. Long-term survival of children and adolescents after traumatic brain injury. Arch Phys Med Rehabil 1998;79:1095-1100.

24. Strauss DJ, Shavelle RM, Anderson TW. Life expectancy of children with cerebral palsy. Pediatr Neurol 1998;18:143-149.

25. State of California (1988-2002). Annual Mortality Tapes, 1988-2002. Sacramento, CA.: Department of Health Services, Center for Health Statistics, Office of Health Information and Research.

26. State of California, Department of Finance, Race/Ethnic Population with Age and Sex Detail, 1970-1989. 1998.

27. State of California, Department of Finance, Race/Ethnic Population with Age and Sex Detail, 1990-1999. 2004.

28. State of California, Department of Finance, Race/Ethnic Population with Age and Sex Detail, 2000-2050. 2004
29. Kahn HA, Sempos CT, Kahn HA. Statistical methods in epidemiology. New York: Oxford University Press, 1989.

30. Rohatgi VK. An introduction to probability theory and mathematical statistics. New York: Wiley, 1976.

31. IARC Working Group on the Evaluation of Carcinogenic Risks to Humans.Tobacco smoke and involuntary smoking. IARC Monogr Eval Carcinog Risks Hum 2004;83:1-1438.

32. Shavelle RM, Strauss DJ, Pickett J. Causes of death in autism. J Autism Dev Disord 2001;31:569-576.

33. Day SM, Strauss DJ, Shavelle RM, Reynolds RJ. Mortality and causes of death in persons with Down syndrome in California. Dev Med Child Neurol 2005;47:171-176.

34. Gottesman RF, Komotar R, Hillis AE. Neurologic aspects of traumatic brain injury. Int Rev Psychiatry 2003;15:302-309.

35. Temkin NR. Risk factors for posttraumatic seizures in adults. Epilepsia 2003;44(suppl 10):18-20.

\section{DISAGREE? AGREE? HAVE A QUESTION? HAVE AN ANSWER?}

Respond to an article in Neurology through our online Correspondence system:

- Visit www.neurology.org

- Access specific article on which you would like to comment

- Click on "Correspondence: Submit a response" in the content box

- Enter contact information

- Upload your Correspondence

- Press Send Response

Correspondence will then be transmitted to the Neurology Editorial Office for review. Accepted material will be posted within 10-14 days of acceptance. Selected correspondence will subsequently appear in the print Journal. See our Information for Authors at www.neurology.org for format requirements. 